\title{
Properties of Solar Radiation Components Reflected by the Sea Surface: - A Case of Jeju Island, South Korea -
}

\author{
Uno Fumichika ${ }^{1 *}$, Yousay Hayashi ${ }^{1}$, Soo-Jin Hwang ${ }^{2}$ and Hae-Dong Kim ${ }^{3}$ \\ ${ }^{1}$ Graduate School of Life and Environmental Science, University of Tsukuba, Tsukuba 305-0001, Japan \\ ${ }^{2}$ Department of Earth Science Education, Pusan National University, Pusan 609-735, Korea \\ ${ }^{3}$ Department of Global Environment, Keimyung University, Daegu 704-701, Korea \\ (Received May 24, 2011; Revised June 15, 2011; Accepted June 24, 2011)
}

\section{해수면에 의해 반사된 태양복사 성분의 특성: 남한의 제주도 사례}

\author{
Uno Fumichika ${ }^{1 *}$ - Yousay Hayashi ${ }^{1} \cdot$ 황수진 $^{2} \cdot$ 김해동 3 \\ 1일본 쓰쿠바대학교 생명환경과학대학원, ${ }^{2}$ 부산대학교 지구과학교육과, ${ }^{3}$ 계명대학교 지구환경학과 \\ (2011년 5월 24일 접수; 2011년 6월 15일 수정; 2011년 6월 24일 수락)
}

\begin{abstract}
Solar radiation components reflected by the sea surface $\left(\boldsymbol{R}_{s s} \uparrow\right)$ are additional energy sources comprising the solar radiation regime. Previous studies, based on observational approaches, indicated that $\boldsymbol{R}_{s s} \uparrow$ is an available climatological resource. However, an estimation process for $\boldsymbol{R}_{s s} \uparrow$ has not been established. In this case study over Jeju Island in South Korea, we applied a new estimation process to solar radiation modeling and discussed the spatial distribution of $R_{s s} \uparrow$ and its seasonal variation. Our results showed that the illuminated area and the intensity of $R_{s s} \uparrow$ became greatest at the winter solstice and least at the summer solstice. We estimated the illuminated area of $\boldsymbol{R}_{s s} \uparrow$ as it expanded over the southern slope of Jeju Island. At the winter solstice, on a daily basis, the area and intensity of illumination by $\boldsymbol{R}_{s s} \uparrow$ were 182.3 $\mathrm{km}^{2}$ and $0.41 \mathrm{MJ} \mathrm{m}^{-2}$ day $^{-1}$, respectively. Comparing the daily accumulative and instantaneous values of $R_{s s} \uparrow$ intensity, the difference was about 20 times greater in daily cases than in instantaneous cases. On the other hand, for instantaneous values, the $R_{s s} \uparrow$ intensity accounted for up to $33 \%$ of the three components, i.e., direct, diffuse and reflected radiation in winter solstice. In addition, it was estimated that the sea surface reflectance depended on the wind speed. Therefore, in a practical use of this revised model, wind conditions should be considered as a critical factor in estimating $\boldsymbol{R}_{\mathrm{ss}} \uparrow$.
\end{abstract}

Key words: Solar radiation, Reflection by the sea, Topographic shading, Jeju Island

\section{INTRODUCTION}

Over complex terrain, global solar radiation (i.e., the sum of direct and diffuse components) varies intrinsically with the relative position between the sun and the exposed sloping surface. The primary energy used for plant growth is restricted by global solar radiation and the capacity of the effective energy (which relates to topographic properties) is defined as climatic resources.
Many researchers have focused their attentions mostly on the spatial distribution of solar radiation.

Many studies have attempted to evaluate the sun orbit and the slope geometry (e.g., slope, altitude, and angle direction) for calculating solar radiation over complex terrain (e.g., Boyer and Feldhake, 1991; Dubayah and Loechel, 1996; Wang et al., 2006). Garnter and Ohmura (1968) used not only the sun orbit and the slope geometry but also atmospheric transmissivity and the 
optical air mass. Additionally, Swift (1976) took the seasonal variation of the sun's orbit into account.

In addition to the complexity of the distribution of surface solar radiation intensity over a steep mountainside, it is important to estimate and discuss the shading effects generated by the surrounding topography. Varley et al. (1996) indicated that the surface global solar radiation at a valley floor is $10 \%$ less than those in open areas that are not under the shading effect. Therefore, the shading effect causes the heterogeneous distribution of solar radiation. The characteristics of spatially heterogeneous solar radiation influence meteorological elements. Muller and Scherer (2005) showed the impact of the shading effect on surface temperature. Surface temperature along the valleys decreased about $1.5 \mathrm{~K}$ when the shading effect process was applied to mesoscale weather forecast models.

In addition to direct and diffuse solar radiation, reflected radiation from south-facing areas along the coast is an important component. Wakiyama and Ohba (1997) reported that large amounts of photosynthetically active radiation (PAR) and near infrared radiation (NIR) were observed over the mountain slopes at lower elevation angle of the sun in comparison to the case with the high elevation. They argued that the larger amount of observed radiation was caused by specular reflection from the sea surface.

In relation to this phenomenon, we have an empirical knowledge that reflected components of the solar radiation $\left(R_{s s} \uparrow\right)$ provide a supplementary energy source for quality fruit production. There are many previous studies addressing direct and diffuse solar radiation. However, radiation components caused by reflection from the water surface have not been discussed much. In the present research, we propose the development of a practical model for estimating solar radiation intensity over complex terrain and its $R_{s s} \uparrow$.

\section{STUDY AREA AND DATA}

The study area of the present research is Jeju Island, South Korea, located about $90 \mathrm{~km}$ from the southern end of the Korean Peninsula. It is an isolated island with Mt. Halra (which has the elevation of $1950 \mathrm{~m}$ above m.s.1.). The latitude of Jeju Island $\left(33.5^{\circ} \mathrm{N}\right)$ is almost identical to that of Fukuoka Prefecture, Kyushu, Japan $\left(33.6^{\circ} \mathrm{N}\right)$. Over the foothills of the south side of Jeju Island are areas favorable for orchard production.

To describe the climatic basis, which is required to

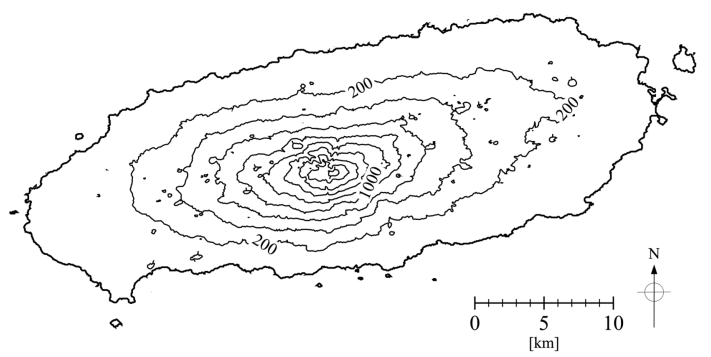

Fig. 1. Topographic map in Jeju Island with contours from 0 to $1800 \mathrm{~m}$ with $200 \mathrm{~m}$ interval.

determine the background condition of solar radiation fields in the model, hourly data for global, direct, and diffuse solar radiation at Fukuoka prefecture were applied. This was done due to a lack of long-term solar radiation observations around Jeju Island and a lack of sufficient representations of the solar radiation regime covering Jeju Island and Fukuoka Prefecture. The radiation data from 1974 to 2005 were provided from the Japan Meteorological Agency (JMA).

Digital Elevation Model (DEM) with a $50 \mathrm{~m}$ grid of spatial resolution was used to calculate the slope geometry, shade effect, and incident angles of all radiation components in a unit area of the surface. The topographical map of Jeju Island with indices to be mentioned later is shown in Fig. 1. The geomorphological characteristics of Jeju Island indicate volcanic topography. The major and minor axes of the island's spindle shape are 73 and $41 \mathrm{~km}$, respectively.

\section{METHODOLOGY}

\subsection{The model framework}

To calculate all solar radiation components over complex terrain, we modified a previous model proposed by Kurose (1991) and Hayashi and Kurose (1997) and appended the calculation process for the reflected component of the solar radiation. The basic framework of the model is described below.

The primary function of the model is to calculate the sun's orbit at arbitrarily preset intervals of time. Since the global solar radiation is defined instantaneously, an interval time of 3 minutes is used. In the present study, it is important to take the shading effect of the surrounding topography into account. First, to calculate the direct component of solar radiation, the angles of elevation of the surrounding ridgelines were computed. Then a resolving angle over the horizontal surface was 
set at 3 degree to detect the corresponding ridgeline.

The subsequent step in the model addresses whether or not the target grid is shaded from direct solar radiation. In this process, it is essential to distinguish the elevation of surrounding ridgelines from the orbital position of the sun because higher ridgelines shade direct solar radiation on the target grid. Furthermore, a parameter for the sky view factor (SVF) is introduced for the computation of the ratio of incoming diffuse to solar radiation. The SVF indicates the ratio of the amount of the sky hemisphere subtended by a horizontal surface.

Prior to the practical estimation for the direct and diffuse solar radiation components on the ground surface, this model requires the proportions of direct and diffuse components to global solar radiation on an open ground surface, as a background over the extent of Jeju Island and Fukuoka stations.

\subsection{Calculations of $\boldsymbol{R}_{s s} \uparrow$}

The area facing the sea receives the reflected component as supplementary energy on the ground. The incident angle of the reflected ray illuminates below the horizon into the ground. Here we assume that the reflected ray is defined only under a process of specular reflection at the sea surface. Thus, the incident angle of the reflected component $\left(\theta_{R}\right)$ is uniquely determined by the solar incidence angle $\left(\theta_{S}\right)$. Naturally, azimuth angle of reflected ray is same as solar azimuth angle. The total energy received by such surfaces depends on the
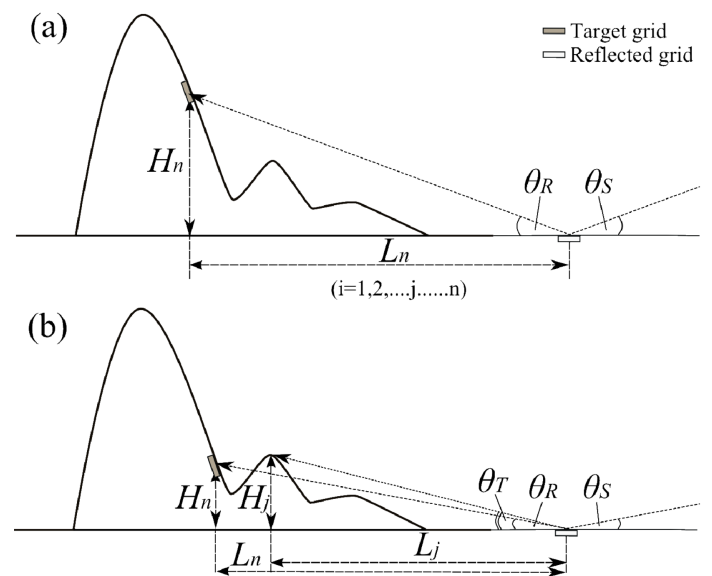

Fig. 2. The processes of $R_{s s} \uparrow$ calculation for (a) directly illuminated case and (b) shaded case for a target slope. The valued of $H$ is the height from target grid to the reflected grid and $L$ is the horizontal distance between target grid and reflected grid. slope angle and direction, solar zenith angle, and incidence angle from the sea in addition to the shading effect around the ridgeline (see Fig. 2).

The required conditions for calculating the $R_{s s} \uparrow$ on sloped surfaces are as follows.

$$
\theta_{R}=\theta_{i T} \quad(i=1,2, \ldots, n)
$$

and

$$
\theta_{i T}=\tan ^{-1} \frac{H_{i}}{L_{i}} \quad(i=1,2, \ldots, n)
$$

where $i$ is a grid number between the target and reflected grids (water surface only). And, $n$ is the number of grids. $\theta_{i T}$ is the elevation angle of the ridgeline, and $H_{i}$ is the height of $i$ th grid to reflected grid. $L_{i}$ is the distance between the $i$ th grid and the reflected grid. If $\theta_{R}$ has the following condition,

$$
\theta_{R}<\operatorname{Max}\left(\theta_{i T}\right) \quad(i=1,2, \ldots, n)
$$

then this condition represents that higher terrain than target grid height exists between target grid and reflected grid (Fig. 2b). Reflected components are scattered by the ridgeline terrain. Furthermore, if the identified reflected grid is located beyond the celestial horizon, the reflected component does not reach the target grid. The distance of the celestial horizon $\left(L_{c e l}\right)$ is described as:

$$
L_{c e l}=r_{E} \cdot \cos ^{-1}\left\{r_{E} /\left(r_{E}+H_{i}\right)\right\}
$$

Here $r_{E}$ is the earth radius $(\sim 6371 \mathrm{~km})$. Because the energy of the reflected component from the ground is negligibly small in comparison to that from the water surface, we eliminated the reflected component from the ground surface in the computations of the $R_{s s} \uparrow$ process.

\section{RESULTS AND DISCUSSION}

\subsection{Distribution of the total radiation energy and $\boldsymbol{R}_{\text {ss }} \uparrow$}

The distributions of the estimated total radiation energy $\left(R_{\text {total }}\right)$ (i.e., the sum of direct and diffuse components and $R_{s s} \uparrow$ ) and $R_{s s} \uparrow$ under clear sky conditions over Jeju Island are shown in Fig. 3 for both solstices and the autumn equinox. Regarding the distribution characteristics of solar radiation, we omitted the spring equinox because the sun's orbit at this time is almost identical to that of the autumn equinox.

The illuminated $R_{\text {total }}$ showed obvious spatial differences between the northern and southern ground sur- 

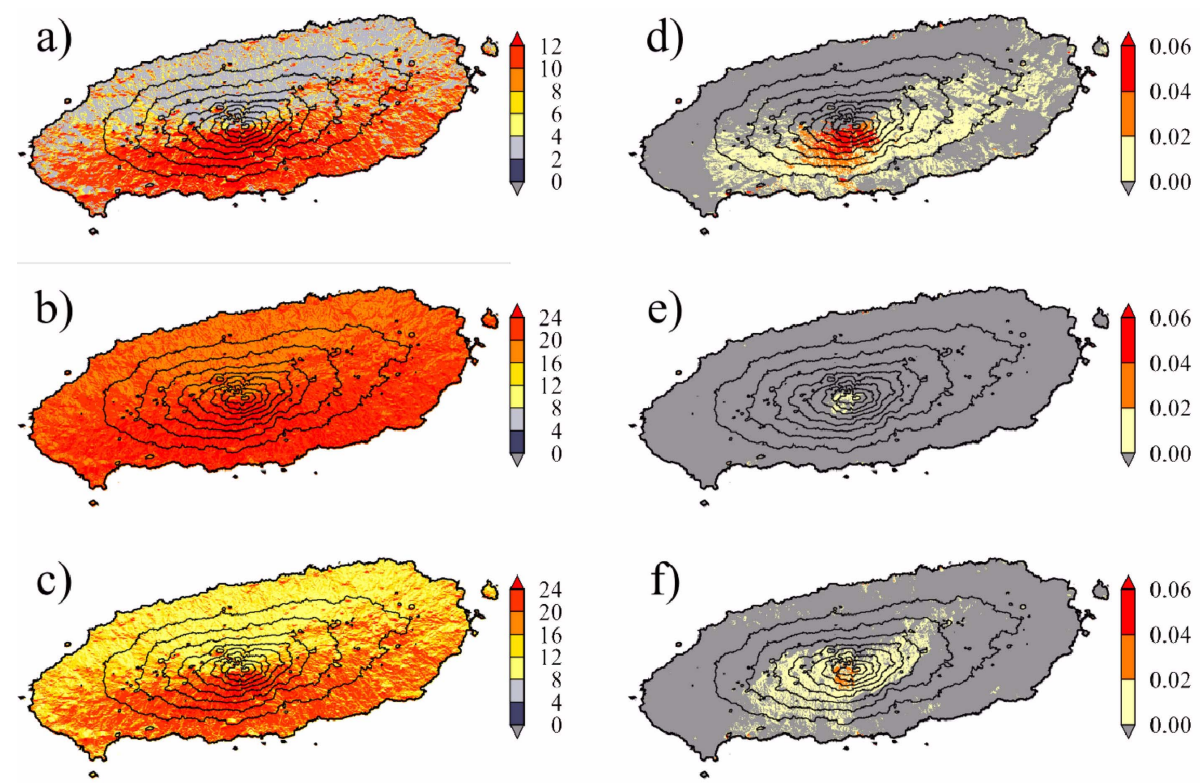

Fig. 3. Spatial distributions of clear sky $R_{\text {total }}(\mathrm{a}, \mathrm{b}, \mathrm{c})$ and $R_{s s} \uparrow(\mathrm{d}, \mathrm{e}, \mathrm{f})\left(\mathrm{MJ} \mathrm{m}^{-2}\right.$ day $\left.{ }^{-1}\right)$ in winter (upper panels) and summer solstice (middle panels), and autumn equinox (lower panels). Contour is same as Fig. 1.

face. At the winter solstice, the difference between north and south was four times greater (Fig. 3a). The north-south difference in the illuminated $R_{\text {total }}$ was observed throughout the year although the difference decreased as the summer approached (see Figs. $3 \mathrm{~b}$ and $3 c)$. The spatial difference and its seasonal variability resulted from the shading effect of the Mt. Halla, which scattered the direct component of global solar radiation. Such an effect becomes prominent in high-elevation areas. Additionally, the areas affected and the scattering of energy by the shading effect depend on the solar zenith angle. Therefore, spatial distribution of $R_{\text {total }}$ shows seasonal variation.

The spatial distribution of $R_{s s} \uparrow$ was different from that of $R_{\text {total }}$. The spatial and seasonal variations of $R_{s s} \uparrow$ are shown in Fig. 3 (right side). The $R_{s s} \uparrow$ intensity was lower than that of $R_{\text {total }}$ because the illumination time of $R_{s s} \uparrow$ was less than 1 hour in all seasons. Almost all of the areas illuminated by $R_{s s} \uparrow$ were extending over the zones of middle and higher altitudes facing the southern slope. At the winter solstice, reddish colorations indicate the area being illuminated by greater energy even though the values were estimated at approximately $0.41 \mathrm{MJ} \mathrm{m}^{-2}$ day $^{-1}$ (Fig. 3d). The illuminated areas of $R_{s s} \uparrow$ extended widely over the east and west portions of the slopes because the direction of rays at sunrise/sunset is extended by $62^{\circ} /-62^{\circ}$ (in this case,

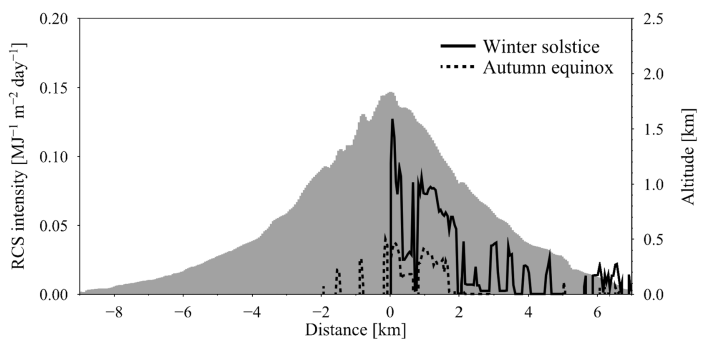

Fig. 4. $R_{s s} \uparrow$ intensity on the north-south cross section at winter solstice (solid line) and autumn equinox (dashed line). Gray shade shows topography. In abscissa axis, location of the summit is referenced at $0 \mathrm{~km}$ (south: positive, north: negative).

zero degrees corresponds to the south). At the equinox (Fig. 3f), the direction shifts more easterly and westerly at sunrise and sunset, respectively. Thus, the illuminated areas are limited to higher altitude slopes because the sun orbit shifts the zenith as summer approaches.

Figure 4 shows the $R_{s s} \uparrow$ intensity at the winter solstice and autumn equinox along a north-south cross section of the mountain's summit. As the incidence angle at the $R_{s S} \uparrow$ on a steeply sloped surface approached perpendicular, the $R_{S S} \uparrow$ intensity became relatively large at high altitude zones compared to that at low altitude. In addition, at the equinox, certain $R_{s s} \uparrow$ is appearing on the northern side of the summit. The $R_{s S} \uparrow$ 


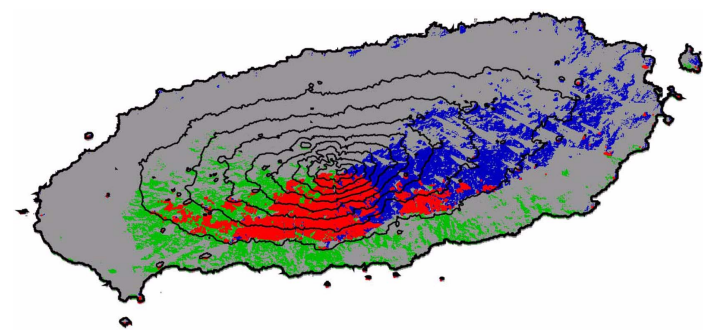

Fig. 5. Time zones of $R_{s S} \uparrow$ illuminated slope through a day at winter solstices, Blue: morning (from 7:46 to 8:15 in LST), Green: evening (from 17:20 to 17:45 in LST), Red: overlapped (from morning (blue) and evening (green)). Contour is same as Fig. 1.

distribution difference between the winter solstice and autumn equinox is caused by the difference in directions at sunrise and sunset. Thus, $R_{s s} \uparrow$ intensity and distribution depend on the sun's orbit.

Durations of the illuminated time by $R_{s s} \uparrow$ are distinguished for a period before noon and for a period of afternoon. The illuminated areas are shown using three categories in Fig. 5. Blue dots represent the areas affected by $R_{s s} \uparrow$ in the morning (from $07: 45$ to $08: 15$ in LST), green dots in the evening (from 17:20 to 17:45 in LST), and red dots for the overlapping periods in the morning and evening in winter solstice. As shown by the red dots, there is significant $R_{s s} \uparrow$ exposure in the middle to high altitude zones of the slope facing the sea (see Fig. 3d). On the other hand, the green dots show that it is only in the afternoon that the $R_{s s} \uparrow$ pours its radiation energy into the periphery zone of the southern foothills extending lower than $200 \mathrm{~m}$ in altitude.

\subsection{Seasonal change of $\boldsymbol{R}_{s s} \uparrow$}

We estimated the seasonal variation of solar radiation by the model using climatological background (Fig. 6) of direct and diffuse radiation observed under clear sky conditions from 1974 to 2005 . The solar radiation properties of this island are shown in Table 1. Daily global solar radiation reaches $28.24 \mathrm{MJ} \mathrm{m}^{-2} \mathrm{day}^{-1}$ at the summer solstice and reduces to $11.41 \mathrm{MJ} \mathrm{m}^{-2} \mathrm{day}^{-1}$ at the winter solstice. Contrary to the seasonality of global

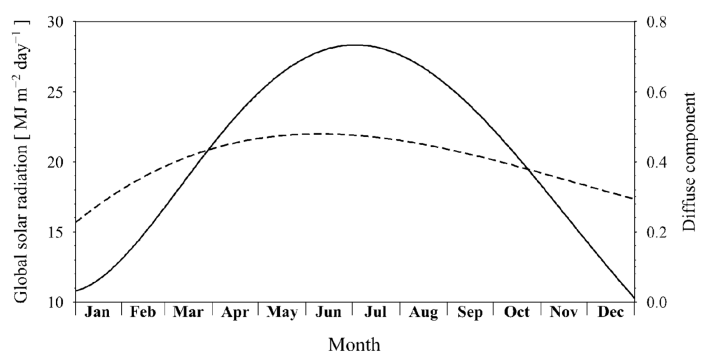

Fig. 6. Seasonal variation of global solar radiation (solid line) and diffuse component (property of diffuse radiation in global solar radiation) (dashed line) for model input data.

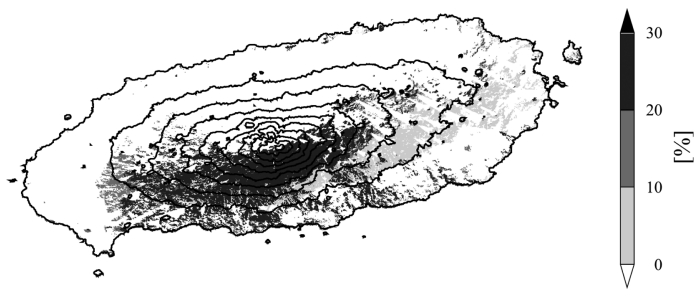

Fig. 7. Distribution of $\left(R_{s s} \uparrow / R_{\text {total }}\right)$ max at winter solstice. Contour is same as Fig. 1.

solar radiation, the $R_{s s} \uparrow$ intensity showed 0.04 and $0.41 \mathrm{MJ} \mathrm{m}^{-2}$ day $^{-1}$ at the summer and winter solstices, respectively. There is a major difference between $R_{s s} \uparrow$ and global solar radiation intensity.

However, from an instantaneous point of view, the $R_{s s} \uparrow$ accounts for $10 \sim 30 \%$ of the global solar radiation (see Table 1). Fig. 7 shows the distribution of the maximum values of the $R_{s s} \uparrow$ ratio $\left(\left(R_{s s} \uparrow / R_{\text {total }}\right)_{\max }\right)$ throughout the day. It must be noted that the timing of $\left(R_{s s} \uparrow /\right.$ $\left.R_{\text {total }}\right)_{\max }$ differs on each grid. The percentage of the $\left(R_{s s} \uparrow\right.$ $\left./ R_{\text {total }}\right)_{\max }$ reaches $33 \%$ at the winter solstice. Also, the coverage area spreads as winter approaches.

\subsection{The effect of wind speed on $R_{s s} \uparrow$}

It is noted that solar reflectance from the sea surface depends on wind speed. In the primary process for calculation of $R_{s s} \uparrow$, additional discussion is needed regarding the role of wave conditions on the solar reflectance ratio under windy conditions. Generally, strong wind generates lower reflectance because of the

Table 1. Seasonal variation of concerning properties in this island

\begin{tabular}{lcccc}
\hline \hline & $\begin{array}{c}\text { Global radiation } \\
\left(\mathrm{MJ} \mathrm{m}^{-2} \mathrm{day}^{-1}\right)\end{array}$ & $\begin{array}{c}R_{\text {ss }} \uparrow \\
\left(\mathrm{MJ} \mathrm{m}^{-2} \mathrm{day}^{-1}\right)\end{array}$ & $\begin{array}{c}\left(R_{\text {ss }} \uparrow / R_{\text {total }}\right) \text { max } \\
(\%)\end{array}$ & $\begin{array}{c}\text { Area* } \\
\left(\mathrm{km}^{2}\right)\end{array}$ \\
\hline Winter solstice & 11.41 & 0.41 & 33.4 & 182.3 \\
Summer solstice & 28.24 & 0.04 & 22.5 & 4.5 \\
Equinox & 23.00 & 0.12 & 7.0 & 88.3 \\
\hline
\end{tabular}




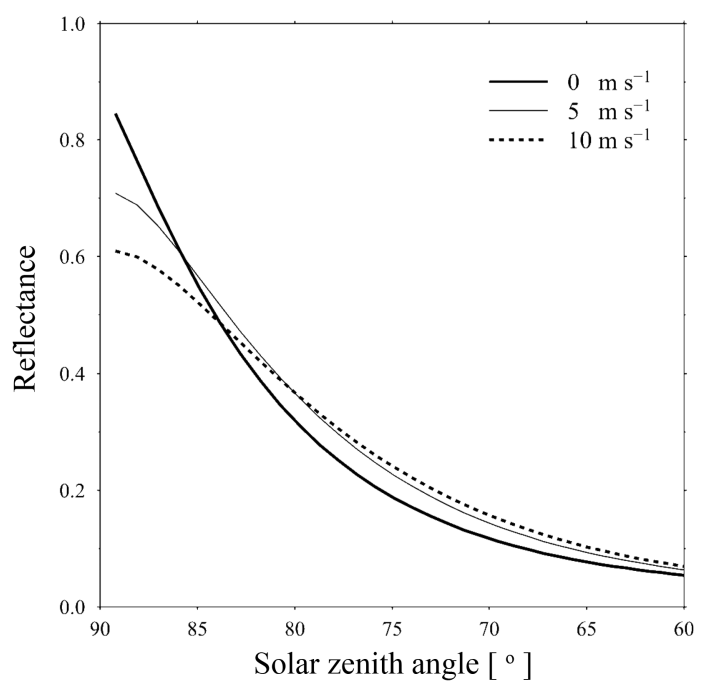

Fig. 8. Relationships between solar zenith angle and reflectance on water surface with wind speed variability.

emergence of foam, and whitecaps over the sea surface (Hwang, 1997). Here, we adopted an algorithm proposed by Haltrin (2002) to estimate the effective reflected solar radiation subject to wave generation under strong wind speeds, which accompanies Fresnel's optical reflection coefficient. Haltrin's function indicates a positive relationship between the solar zenith angle and Fresnel's reflection coefficient.

Figure 8 indicates the wind speed dependence of the sea surface's reflectance. Reflectance at larger solar zenith angle varied with wind speed. However, the difference became smaller when the solar zenith angle was around 85 degrees. Reflectance decreased as the solar zenith angle decreased, but the rate of decrease is less than that under windy conditions. For example, reflectance under $10 \mathrm{~m} \mathrm{~s}^{-1}$ wind speed was smaller than those under calm conditions at large solar zenith angle. This indicates that the $R_{s s} \uparrow$ will be reinforced under relatively strong wind conditions when the solar zenith angle is smaller than approximately 85 degrees. Inversely, reflectance at solar zenith angle greater than 85 degrees weakens under this condition. Fig. 9 shows the frequency of the solar zenith angle when $R_{s s} \uparrow$ illuminates the slope through a day at two solstices and at autumn equinox. The frequency about solar zenith angle greater than 85 degree accounts for $80 \%$ of the total. Therefore, the wind speed factor was not negligible when calculating $R_{s s} \uparrow$ intensity.

To focus on the properties of $R_{s s} \uparrow$ intensity over

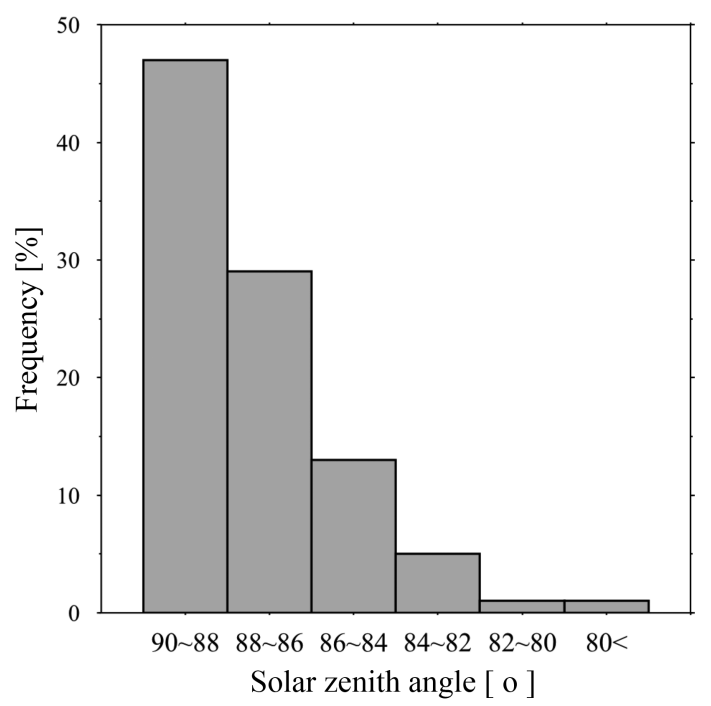

Fig. 9. The frequency of solar zenith angle which $R_{s s} \uparrow$ illuminated the slopes surface in two solstices and autumn equinox.

complex terrain, the first half of this study is simplified to ignore the effective reflectance of the sea surface under windy conditions.

\section{SUMMARY AND CONCLUSION}

In this study, we presented a method of estimating $R_{s s} \uparrow$. Then we applied this new $R_{s s} \uparrow$ estimation process to a solar radiation estimation model including the solar radiation scattering effect around terrain. The particulars of the method are: 1) assumption of specular reflection from the sea surface, 2) consideration of the scattering effect between the sea surface and the slope, and 3) exception of $R_{s s} \uparrow$ from beyond the celestial horizon.

Our results show that the spatial distribution of $R_{s s} \uparrow$ intensity expanded over the southern slope, and high altitude slopes received more $R_{s s} \uparrow$. The intensity of $R_{s s} \uparrow$ became weakest with least amount of receiving area around the summer solstice and then increased as the winter solstice approached. The peak $R_{s s} \uparrow$ intensity appeared on the southern slope at the center of the mountain because the slope received $R_{s s} \uparrow$ at both sunrise and sunset. Daily $R_{S S} \uparrow$ intensity accounted for only $4 \%$ of the daily global solar radiation. However, instantaneous values of $R_{s s} \uparrow$ intensity accounted for $33 \%$ of the global solar radiation.

Considering $R_{s s} \uparrow$ from the southeast to southwest 
slopes, the $R_{s s} \uparrow$ receiving area and intensity thereof were greatest around the winter solstice. Daily $R_{s s} \uparrow$ intensity had little effect on daily global solar radiation intensity. However, the instantaneous value of $R_{s s} \uparrow$ had a strong impact on instantaneous global solar radiation intensity at sunrise and sunset.

Wind speed was an important factor influencing the variation of $R_{s S} \uparrow$, which affect the strength of ocean waves and foams. At large solar zenith angle, the reflectance became smaller with a stronger wind condition. The effect of wind conditions on reflectance increased when the solar zenith angle was greater than $85^{\circ}$, which accounted for more than $80 \%$ of the total over the island.

We investigated the spatial and temporal variability of $R_{s s} \uparrow$ over complex terrains. The characteristic spatial distribution of $R_{s s} \uparrow$ manifested over the slopes around the top of mountain at sunrise and sunset in winter solstice. In comparison to the magnitude of $R_{\text {total }}$, that of the daily accumulated $R_{s s} \uparrow$ was very small because its duration of the illumination was restricted to only several tens of minutes at sunrise and sunset. However, the instantaneous value of $R_{s s} \uparrow$ accounted for 10 to $30 \%$ of $R_{\text {total }}$, indicating an important role of $R_{s s} \uparrow$ especially over slope surfaces.

In this study, we assumed the processes under clear sky conditions and thus did not take the attenuation effects of clouds on solar radiation intensity into account. Further modeling efforts should incorporate cloud effects for better understanding of the solar radiation properties including $R_{s s} \uparrow$.

\section{적 요}

해안지대의 에너지평형을 결정짓는 복사성분 가운데 주변 바다로부터 반사되는 양을 무시할 수 없지만 아 직 해수면 반사성분을 추정할 수 있는 방법이 확립되 지 못한 실정이다. 본 연구에서는 새로운 추정방법을 고안하여 해수면 반사성분의 지리적, 계절적 분포양상 을 모의하였으며, 그 결과 영향권의 면적과 수광량 모 두 동지 무렵에 가장 크고 하지 무렵에 가장 적다는 것을 밝혔다. 이 방법을 제주도 한라산 사면에 적용할 경우 동지 무렵의 해수면 반사영향권은 $182.3 \mathrm{~km}^{2}$ 이고 하루 누적 수광량은 $0.41 \mathrm{MJ} \mathrm{m}^{-2}$ 이었다. 순간값의 경우 일 중 시간에 따라 전체 일사수광량 가운데 해 수면 반사성분이 최대 $33 \%$ 를 차지하였다. 이 모형에 의해 해수면 반사성분을 추정할 때 가장 큰 영향을 주는 기상요인은 풍속으로 나타났다. 따라서, 현실적
인 산출을 위해서는 모형에서 풍속을 고려해 주어야 만 한다.

\section{ACKNOWLEDGMENTS}

We would like to express our thanks to the reviewers for their profitable comments improving the quality of the manuscript. We also acknowledge Prof J. I. Yun, Kyunghee University of Korea, for his warm advice on this study. Thanks is also goes out to Ms. O. Lamjav, Institute of Meteorology and Hydrology of Mongolia, for her suggestive assistance.

\section{REFERENCES}

Boyer, G. D., and Feldhake, M. C., 1991: Distributions of horizon-limited direct beam potential radiation in steep pastures, Earth Surface Processes and Landforms 16, 1-10.

Dubayah, R. and Loechel, S., 1997: Modeling topographic solar radiation using GOES data, Journal of Applied Meteorology 36, 141-154.

Garnter B. J., and A. Ohmura, 1968: A Method of Calculating the Direct Shortwave Radiation Income of Slopes, Journal of Applied Meteorology 7, 796-800.

Haltrin, 1. V., 2002: Algorithm and code to calculate specular reflection of light from a wavy water surface, Proceedings of the Seventh International Conference on Remote Sensing for Marine and Coastal Environments, 20-22 May, 2002, Miami, Florida, USA.

Hayashi, Y., and Y., Kurose, 1997: Spatial distribution of radiation fields estimated by a $250-\mathrm{m}$ mesh model in mountains-agricultural regions, Geographical Review of Japan 70A-5, 307-320. (In Japanese)

Hwang, A. P., 1997: A study of the wavenumber spectra of short water waves in the ocean. Part2: spectral model and mean square slope. Journal of Atmospheric and Oceanic Technology 14, 1174-1186.

Kurose, Y., 1991: Estimation model for spatial distribution of solar radiation over complex terrains using 250-m grid size data. Journal of Agricultural Meteorology 47(2), 95-99. (In Japanese)

Swift, L. W. Jr., 1976: Algorithm for Solar Radiation on Mountain Slopes, Water Resources Research 12(1), 108-112.

Muller D. M., and D, Scherer, 2005: A grid- and subgridscale radiation parameterization of topographic effects for mesoscale weather forecast models, Monthly Weather Review 133, 1431-1442.

Varley, M. J., K. J. Beven, and H. R. Oliver, 1996: Modeling solar radiation in steeply sloping terrain, International Journal of Climate 16, 93-104.

Wakiyama, Y., and K., Ohba, 1997: Effect of radiation reflected from the sea on the spectrum of diffuse radia- 
tion at the canopy of orchard on the slope facing to the sea, Journal of Agricultural Meteorology 53(2), 111-118. (In Japanese)

Wang, Q., J. Tenhunen, M. Schmidt, O. Kolcun, and M.
Droesler, 2006: A Model to Estimate Global Radiation in Complex Terrain, Boundary-Layer Meteorology 119, 409-429. 